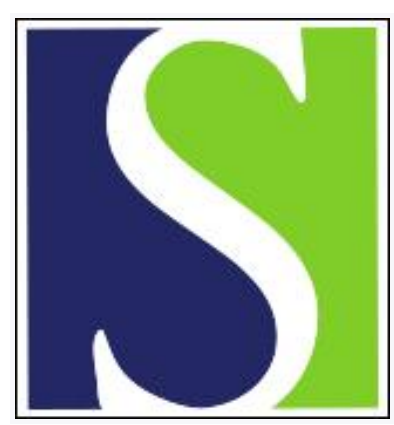

Scand J Work Environ Health 1981;7(3):190-195

https://doi.org/10.5271/sjweh.3111

Issue date: Sep 1981

Topographic and size distribution of asbestos bodies in exposed human lungs

by Gylseth B, Baunan R

Affiliation: Institute of Occupational Health, Oslo 1, Norway.

Refers to the following text of the Journal: $1981 ; 7(2): 101-108$

Key terms: asbestos; asbestos body; distribution; exposure; human lung; lung; lung tissue; preparation technique; scanning electron microscopy; size distribution; topographic distribution

This article in PubMed: www.ncbi.nlm.nih.gov/pubmed/20120584

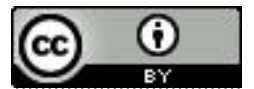




\title{
Topographic and size distribution of asbestos bodies in exposed human lungs
}

\author{
by Bjørn Gylseth, MSc, Randi Baunan, MSc ${ }^{\prime}$
}

\begin{abstract}
GYLSETH B, BAUNAN R. Topographic and size determination of asbestos bodies in exposed human lungs. Scand $j$ work environ health 7 (1981) 190-195. The concentration and the length distribution of asbestos bodies in exposed human lungs have been determined in autopsy material by scanning electron microscopy after two different methods for preparing the tissue samples. The results demonstrate that the number of bodies vary between the right and left lung, as well as between the different lobes of a lung. The length distribution between the different lungs was, on the average, more or less the same; however small differences occurred between the different lobes. It was further shown that drying the tissue pieces before the analyses affected both the number and the length of the bodies. Examples of different types of asbestos bodies are presented, and their possible biological activity is discussed.
\end{abstract}

Key terms: Iung tissue, scanning electron microscopy, preparation techniques.

Fibrous particles may be ingested by phagocytic cells forming ferruginous or asbestos bodies in vivo. The formation of such bodies in different animal species and in humans has been discussed by other authors $(2,8,11,12)$. The animal experiments have shown that serpentine and amphibole asbestos are converted into bodies in more or less the same way $(2,12)$. However, analyses of industrially exposed human lungs have shown that asbestos body formation occurs more frequently on the straight amphibole fibers than on the silky chrysotile bundles $(3,5)$. This phenomenon may be due to several factors, eg, lung clearance, fiber diameter, and length.

It has clearly been established that fibers shorter than $10 \mu \mathrm{m}$ very rarely form asbestos bodies $(10,11)$. In human lung the detoxifying mechanisms leading to the formation of coated fibers also act on nonasbestos fibers (5). Talc bodies and amphi-

1 Institute of Occupational Health, Oslo, Norway.

Reprint requests to: $\mathrm{Mr} \mathrm{B}$ Gylseth, Institute of Occupational Health, PO Box 8149 Dep, Oslo 1, Norway. bole (taconite) bodies have been reported $(1,7)$.

The analysis of fibers in tissue samples by microscopic techniques involves several preparative steps which might influence both the fiber concentration and the actual length distribution. Recent data published by Morgan \& Holmes (10) give the ratio, based on light microscopic analysis, between coated and uncoated fibers in human lung tissue. Such data are biased as long as only a small part of the uncoated fibers in lung tissue samples can be detected by optical microscopy.

In the present paper some methodological aspects of tissue preparation are discussed. The topographic distribution of asbestos in exposed human lungs is indicated, along with interlobar number and body size distribution variations.

\section{Subjects}

Whole lung sets fixed in formaldehyde were obtained from two patients who died of asbestos-related diseases. The subject referred to as $\mathrm{A}$ had been employed in insulation work for many years. This patient suffered from carcinoma of the left 
lung, moderate asbestosis, and emphysema when he died. Subject B had been working in an asbestos cement plant for several years and had died of malignant pleural mesothelioma of the left lung.

\section{Methods}

Adjacent samples of the central parts of each lung lobe were cut and either digested in sodiumhypochlorite or dried and ashed in a low-temperature plasma asher. When the tissue pieces were sampled, tumor-infiltrated tissue was avoided, as were areas with gross fibrosis and emphysema. A complete digestion was obtained by keeping the hypochlorite/tissue suspension at $60-70^{\circ} \mathrm{C}$ for a few hours. Then $5 \mathrm{ml}$ of diethyl ether was added, and the tube thoroughly shaken before it was centrifuged at $4,000 \mathrm{r} / \mathrm{min}$ for $20 \mathrm{~min}$. After centrifugation most of the ether was sucked off and the procedure repeated. The suspension was kept at $60-70^{\circ} \mathrm{C}$ for a few minutes for removal of the residual ether. Unreacted hypochlorite was neutralized by $1 \mathrm{M}$ hydrochloric acid, sonicated for $5 \mathrm{~min}$ and filtered onto a $0.2 \mu \mathrm{m}$ Nuclepore membrane.

Specimens for ashing were cut in small pieces and dried to a constant weight. In order to obtain a sufficient number of asbestos bodies in each sample, we cut approximately $500 \mathrm{mg}$ of wet tissue, an amount corresponding to approximately $50 \mathrm{mg}$ of dried tissue. A complete removal of the organics was obtained after about $2 \mathrm{~h}$ in the low-temperature plasma asher. The residue was suspended in $0.5 \mathrm{M}$ hydrochloric acid, sonicated for $5 \mathrm{~min}$, and filtrated onto a $0.2-\mu \mathrm{m}$ Nuclepore membrane. All the samples were coated with gold before the analysis in the scanning electron microscope. The concentration of uncoated fibers is normally evaluated at a magnification of $4,500 \times$. As asbestos bodies are much larger and less frequent than uncoated fibers, we evaluated them at a magnification of $1,500 \times$ in order to obtain a sufficient number of bodies. Either 100 bodies or 200 view fields were evaluated directly on the microscope screen in the slow scanning mode. Only fibers with a well-defined ferroprotein coating were counted. For further details of the methods, see the report by Gylseth et al (6).

\section{Results}

The number of asbestos bodies in the central parts of the lung lobes of the two lung sets are given in table 1 . As shown, the number of fibers coated were generally higher in the upper lobes than in the lower ones, except for the right middle lobe of subject $A$ and the right upper lobe of subject $B$.

Fig 1 shows that there is a fairly good correlation between the two maceration methods applied. However, the low-temperature plasma ashing method gives a slightly higher concentration of bodies than the wet digestion method due to the long bodies breaking during tissue shrinkage when it is dried. This phenomenon is even more clearly demonstrated in fig 2, showing the length distribution of the bodies in subject $A$ after the different maceration methods have been applied. The count median length (CML) has changed from $43 \mu \mathrm{m}$ to approximately $15 \mu \mathrm{m}$ after the drying, an indication, on the average, that fibers of this size break at least at two sites during drying. In a normal situation the very long fibers break several times, and the shorter ones do not break at all. It is also shown in fig 2 that the individual length distribution differs. For subject B the CML is $31 \mu \mathrm{m}$. The size distribution of bodies resulting from the different methods is only given for subject $\mathrm{A}$, as the analysis of the low-temperature ashed samples from the other subject gave exactly the same pattern of length distribution.

In fig 3 the length distribution in the different lung lobes of subject $\mathrm{A}$ is given and indicates that there was a significant difference between the left upper and lower lobes, whereas the differences between the lobes of the right lung were very small. The same pattern was obtained for subject $B$.

Typical asbestos bodies formed on amphiboles are shown in fig 4-7. Fig 6 and 7 indicate that the coating of the fibers/ bodies occurs more than one time; in other words the bodies themselves might possess a toxic potential to the tissue. The ferroprotein fragment shown along with the body in fig 7 indicates a layer structure produced by another coating process.

In our studies of exposed human lungs, bodies formed on chrysotile asbestos are 
Table 1. Number of asbestos bodies $\times 10^{3}$ per gram of dried tissue as determined by scanning electron microscopy at a magnification of $1,500 \times$ in the different lung lobes of two lung sets macerated in two different ways.

\begin{tabular}{lcc}
\hline & $\begin{array}{c}\text { Wet digestion } \\
\text { in sodium- } \\
\text { hypochlorite }\end{array}$ & $\begin{array}{c}\text { Low-tempera- } \\
\text { ture plasma } \\
\text { ashing }\end{array}$ \\
\cline { 2 - 3 } & & \\
Subject A & 2,213 & 3,315 \\
Right upper lobe & 1,359 & 2,496 \\
Right middle lobe & 2,013 & 3,997 \\
Right lower lobe & 361 & 749 \\
Left upper lobe & 50 & 254 \\
Left lower lobe & & \\
Subject B & 582 & 707 \\
Right upper lobe & 983 & 2,590 \\
Right middle lobe & 188 & 247 \\
Right lower lobe & 1,264 & 1,282 \\
Left upper lobe & 108 & 245 \\
Left lower lobe & & \\
\hline
\end{tabular}

a Dry weight determined by the drying of adjacent samples and the determining of the dry/wet weight ratio.

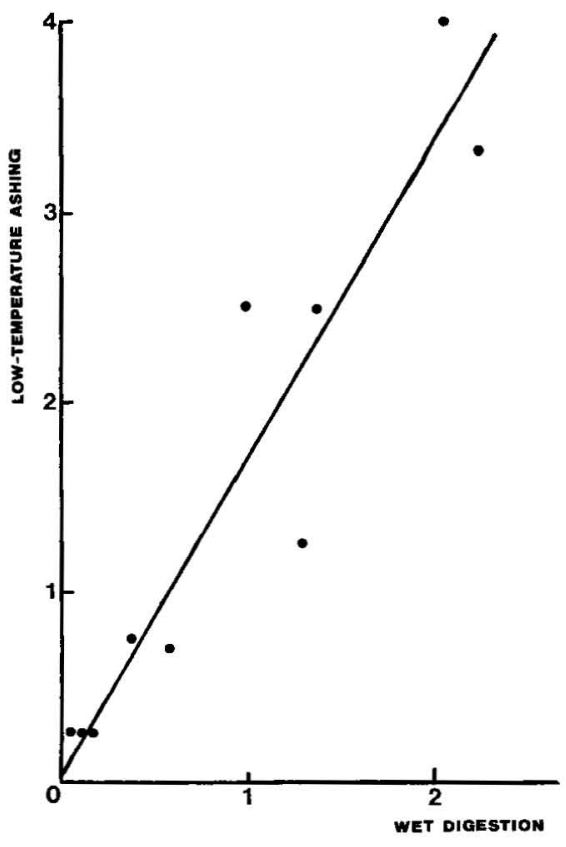

Fig 1. Asbestos body concentration in adjacent tissue samples prepared either by wet digestion or by low-temperature plasma ashing - Million asbestos bodies per gram of dried tissue on both scales.

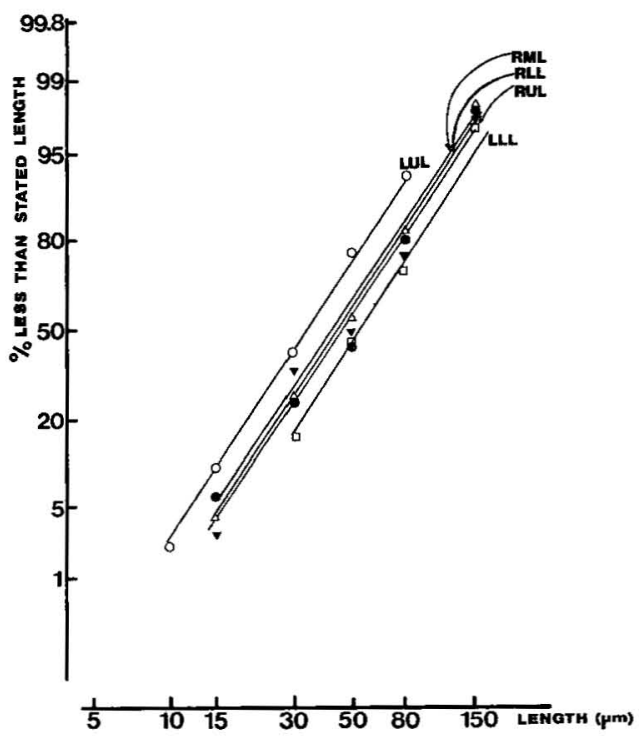

Fig 3. Length distribution of asbestos bodies in the different lung lobes of subject $A$. [O = left upper lobe (LUL), $\square=$ left lower lobe (LLL), $\bullet=$ right upper lobe (RUL), $\boldsymbol{\nabla}=$ right middle lobe (RML), and $\Delta=$ right lower lobe (RLL)]. 


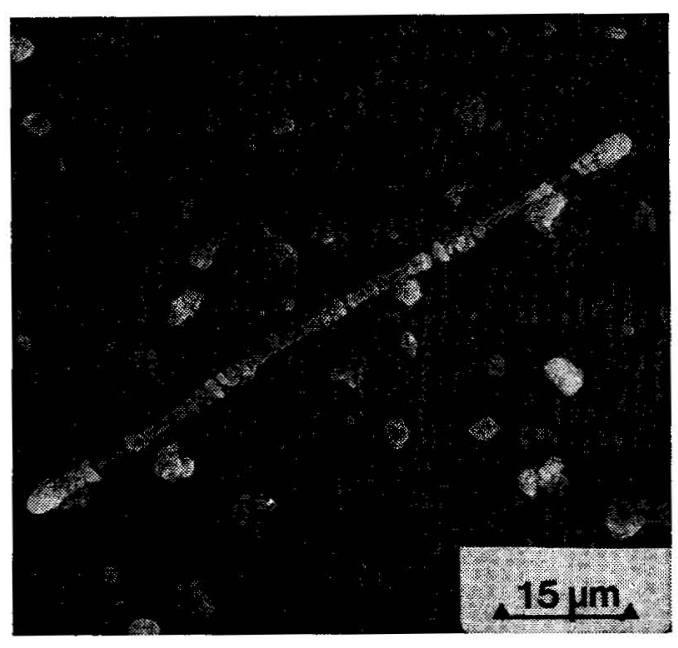

Fig 4. Asbestos body from the lung tissue $(1,000 \times)$.

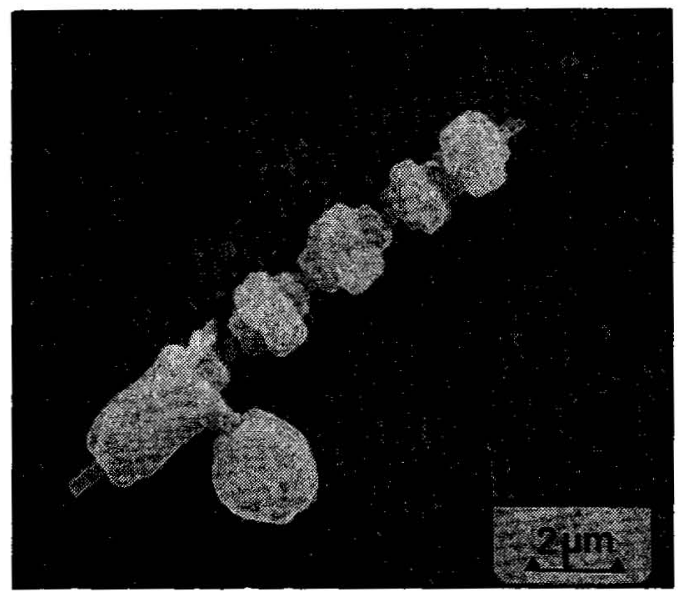

Fig 6. Asbestos body with a shape indicating that it has undergone coating twice $(4,800 \times)$.

rarely seen. The analysis of lung tissue from another case revealed a bundle of chrysotile fibers, as identified by energy dispersive $\mathrm{X}$-ray microanalysis, heavily coated by ferroproteins. The bundle is shown at different magnifications in fig 8 and 9 .

\section{Discussion}

Inhaled asbestos fibers are attacked by alveolar macrophages attempting to detoxify the fibers. Previous data published by

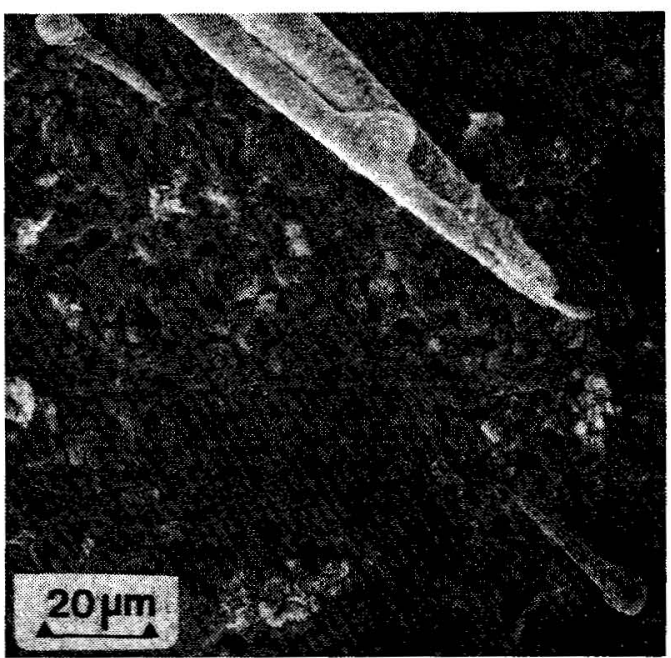

Fig 5. Ferroprotein clubs formed on the ends of a thin amphibole fiber $(600 \times)$.

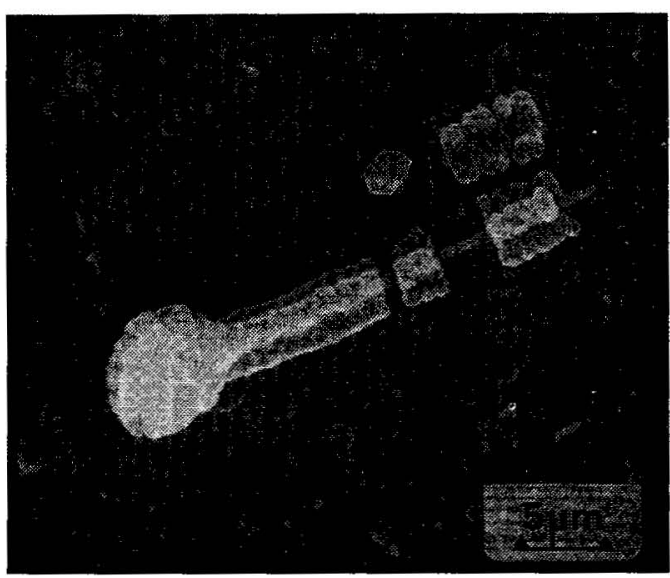

Fig 7. Asbestos body with typical layered structure of the ferroprotein coating $(2,000 \times)$.

Pooley (11) show that the formation of bodies occurs the most frequently on straight, rigid fibers, ie, amphibole asbestos. This finding has been confirmed by Churg \& Warnock (4) and is supported by our data. The work done by Pooley, and more recently by Morgan \& Holmes (10), agrees in that only fibers longer than $10 \mu \mathrm{m}$ form asbestos bodies. In our wetdigested samples only a very few bodies shorter than $10 \mu \mathrm{m}$ were observed. The concentration of asbestos bodies demonstrated in our study corresponds fairly well with those of Morgan \& Holmes (10); 


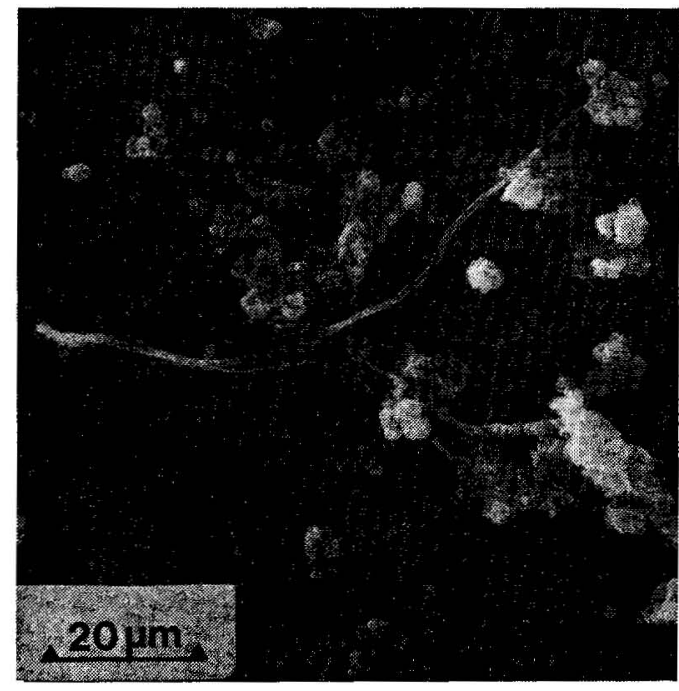

Fig 8. Ferroprotein coating on a chrysotile bundle $(860 \times)$.

it ranged from a few thousand up to several millions of bodies per gram of dried tissue. The length distribution varies from case to case depending on the types of asbestos to which the subjects have been exposed. Normally the CMLs of the bodies vary from $20-50 \mu \mathrm{m}$.

As previously shown by Gylseth et al (6), the shrinkage of the tissue during the drying process breaks long fibers. Such breakage certainly also occurs for asbestos bodies at almost the same extent. Therefore, it must be emphasized that, if fiber length distributions in lung tissue samples are to be determined after the tissue has completely dried and thereby shrunk, a highly biased length distribution will be obtained. The shrinkage will not affect the diameter distribution. This phenomenon is especially important, as length seems to be a very significant factor of the biological potential of the fiber. If specimens that are too large are wet digested, residual debris will cover small fibers and thus give fiber numbers that are too low. Some of these fibers will be detected in a transmission electron microscope, due to to its high penetration power. In this investigation only asbestos bodies, which are rather large compared to most uncoated fibers, were counted and therefore the aforementioned error was minimized.

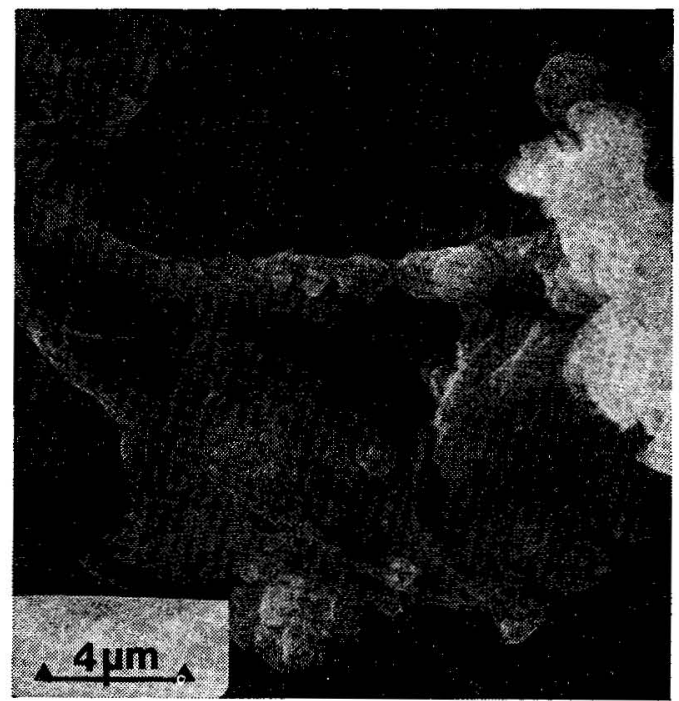

Fig 9. A part of the ferroprotein coating on the chrysotile bundle shown in fig 8 at a magnification of $3,600 \times$.

During tissue shrinkage the long fibers break, and we have evidence of small fibers being lost during the centrifugation/ decantation of suspensions. In conclusion both methods seem to have their advantages and disadvantages.

Different length distributions of fibers in lungs of subjects with different occupations should be expected. In this report it is shown that long asbestos bodies occurred more frequently in subject $A$ (insulator) than in subject $B$ (asbestos cement worker). It is further shown that the upper left lobe contained longer bodies than the lower left lobe, while the variation within the right lobes was small.

McLemore et al (9) have shown that the asbestos bodies in a lung digest possessed a slight cytotoxicity towards human free alveolar macrophages. By scanning electron microscopy it has been shown that surface membrane changes occur after the phagocytosis of asbestos bodies. However, in the lung digest used by McLemore et al, a considerable number of uncoated fibers must have been present and added together with the bodies to the cell cultures. This occurrence might have contributed to the general cytotoxicity revealed. In our investigation we have demonstrated that the bodies in human lungs are attacked and coated more than once, as illustrated 
in fig 6 and 7 , and this finding supports the data published by McLemore et al. However, the asbestos bodies were few in number when compared to the uncoated fibers; therefore, from a toxicity point of view, we believe that the activity against the bodies is of less importance than that against uncoated fibers. The gradual build-up of the ferroprotein layer is contradictory to that reported by Pooley (11) in his study of body replicas in the transmission electron microscope. The scanning electron microscope would be a better tool for the study of morphological images of ferroprotein coatings on fibers.

It has been shown by Suzuki \& Churg (12) and Botham \& Holt (2) that chrysotile also forms asbestos bodies in animals, though maybe in a slightly other way than the amphiboles. Pooley (11) showed that, in analyses of lung tissue samples, asbestos body formation on chrysotile fibers is rare, even in subjects only exposed to this type of fiber. In our study of lung tissue from exposed subjects we rarely found chrysotile bodies. This result may be due to factors such as the rapid clearance of the chrysotile bundles from the human respiratory system or, more likely, the breaking down in vivo of chrysotile asbestos to short and thin fibrils which normally are not quite coated by ferroproteins.

\section{Acknowledgments}

We would like to thank the staff at the pathological departments at the Aker Hospital and the Norwegian Radium Hospital for supplying us with the lung samples.

This manuscript was partly prepared during a stay at the MRC, Pneumoconisois Unit, Penarth, United Kingdom. We gratefully acknowledge the staff at the Unit for their technical help and Dr P Elmes for his valuable comments during the preparation of the manuscript.

\section{References}

1. Berner A, Gylseth B, Levy F. Talc-dust pneumoconiosis: A case report. Acta pathol microbiol scand sect A 89 (1981) $17-21$.

2. Botham SK, Holt PF. Development of asbestos bodies on amosite, chrysotile and crocidolite fibers in guinea-pig lungs. I pathol 105 (1971) 159-167.

3. Churg A, Warnock ML. Analysis of the cores of ferruginous (asbestos) bodies from the general population: I. Patients with and without lung cancer. Lab invest 37 (1977) 280-286.

4. Churg A, Warnock ML. Asbestos fibers in the general population. Am rev respir dis 122 (1980) 669-678.

5. Churg A, Warnock ML, Green N. Analysis of ferruginous (asbestos) bodies from the general population: II. True asbestos bodies and pseudoasbestos bodies. Lab invest 40 (1979) $31-38$.

6. Gylseth B, Baunan RH, Bruun R. Analysis of inorganic fibers in biological samples by scanning electron microscopy. Scand $\mathbf{j}$ work environ health 7 (1981) 101-108.

7. Gylseth B, Norseth T. Amphibole fibers in a taconite mine and in the lungs of the miners. Am $\mathrm{j}$ ind med (in press).

8. Holmes A, Morgan A. Clearance of anthophyllite fibres from the rat lung and the formation of asbestos bodies. Environ res 22 (1980) 13-21.

9. McLemore TL, Mace ML, Roggli V, Marshall MV, Lawrence EC, Wilson RK, Martin RR, Brinkley BR, Greenberg DS. Asbestos body phagocytosis by human free alveolar macrophages. Cancer lett 9 (1980) 85-93.

10. Morgan A, Holmes A. Concentrations and dimensions of coated and uncoated asbestos fibres in the human Iung. $\mathrm{Br} \mathrm{j}$ ind med. 37 (1980) 25-32.

11. Pooley FD. Asbestos bodies, their formation, composition and character. Environ res 5 (1972) $363-379$.

12. Suzuki Y, Churg J. Formation of the asbestos body: A comparative study with three types of asbestos. Environ res 3 (1969) 107-118. 